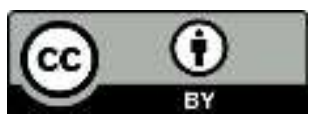

\title{
REDEFINIÇÕES RELIGIOSAS DAS IGREJAS DOS ROQUEIROS E DOS SURFISTAS EM CURITIBA/PR (1990/2010)
}

Religious redefinitions of the churches of the rockers and the surfers in Curitiba-PR (1990-2010)

\author{
Maralice Maschio \\ Doutoranda em História/UFPR/Bolsista CAPES \\ maralicemaschio@gmail.com
}

RESUMO: Esse artigo visa problematizar concepções e práticas de lideranças e membresia das igrejas evangélicas Gólgota e Bola de Neve, cujas experiências individuais e coletivas contrastam com tentativas de construção e representação de identidades coesas. Destaca-se o alargamento do cenário evangélico nos últimos anos, através do uso intensivo das mídias, da reatualização dos rituais, da forte presença da juventude e do aumento da individualidade da religiosidade. Por intermédio de uma entrevista televisiva observa-se, no campo da Análise do Discurso, como igrejas alternativas têm atuado no cenário evangélico pentecostal, redefinido a religiosidade contemporânea, reinterpretado e relativizado doutrinas e costumes.

Palavras-chave: Cenário Evangélic; Igrejas Alternativas; Redefinições religiosas; Mídias; Análise do Discurso.

ABSTRACT: This article intends to discuss concepts and practices of leadership and membership of the Evangelical churches Golgotha and Snowball, whose individual and collective experiences contrast with attempts of construction and representation of cohesive identities. Noteworthy is the extension of the Evangelical landscape in recent years, through extensive use of the media, the actualization of the rituals, the strong presence of youth and increasing individuality of religiosity. Through a television interview, one observes in the field of discourse analysis, how alternative Pentecostal churches have been acting in Evangelical landscape, redefined contemporary religiosity, and reinterpreted and relativized religious doctrines and customs.

Key-words: Evangelical scenario; Alternatives Churches; Religious Resets; Media; Discourse Analysis. 


\section{Introdução}

A entrevista ${ }^{1}$ produzida pelo Programa Destaque, da Emissora SBT, no dia 31 de maio de 2010, com o pastor Pipe, da Comunidade Gólgota e o membro da Bola de Neve Church, Fernando, em Curitiba/PR, disponível na rede, possibilitou a problematização de novos sentidos e contornos de "ser evangélico" na contemporaneidade. Dialogando com tal fonte, pretende-se identificar aspectos do alargamento do cenário evangélico, especialmente nas últimas duas décadas, tais como o uso intensivo de mídias, a reatualização de rituais, a forte presença da juventude e o aumento da individualidade da religiosidade. Consequentemente, observar o crescimento das motivações e instituições religiosas na sociedade contemporânea, possibilita mostrar como o estudo das religiões tem se apresentado um campo em constante expansão.

Concomitantemente, a fonte também permitiu analisar, em paralelo, as igrejas Gólgota e Bola de Neve, explorando como essas duas instituições emergiram num cenário fragmentário de contestação a algumas ordens religiosas e sociais mais tradicionais, ao mesmo tempo em que essa "renovação", "inovação" ou, até mesmo, abertura ao "diferente", parecem colarem-se intrinsecamente a um discurso religioso que se opõe às novas margens da diversidade social tão propugnada nos tempos atuais. Por isso, pretende-se compreender, em termos históricos, as diferentes atuações referentes à juventude evangélica em vista das estratégias delineadas pelas duas igrejas para atraírem um público juvenil, seja pelo uso de mídias (rádio, TV, jornal e Internet), seja pelos reatualizados rituais.

Tendo em vista que a mídia e a religião são os eixos centrais do diálogo, é preciso levar em conta que a relação entre elas não é nova; o próprio cristianismo expandiu-se motivado pela frase "O verbo se fez carne e habitou entre nós (Jo 1, 14) ${ }^{2}$. Se nas sociedades tradicionais a religião tinha uma posição privilegiada como formadora e inspetora dos valores, hábitos, condutas e da visão de mundo, esta posição hoje parece ter sido ocupada pela mídia. Nas sociedades contemporâneas, submetidas ao processo de globalização, acontece um intenso processo de midiatização da cultura e

\footnotetext{
${ }^{1} \mathrm{O}$ presente texto é uma adaptação, utilizando a entrevista televisiva como fonte, do trabalho final da disciplina de Análise do Discurso, do programa de pós-graduação em História da UFPR, ofertada no primeiro semestre de 2013 e também serviu como aporte de discussão para o VII Seminário Nacional e I Seminário Internacional "Religião e Sociedade: O Espaço do Sagrado no século XXI", promovido pelo NUPPER em 2013, cujo simpósio temático escolhido tratou dos eixos religião e mídia.

${ }^{2}$ A BÍBLIA SAGRADA. Traduzida em Português por João Ferreira de Almeida. Revista e Corrigida no Brasil. Ed. 1995. São Paulo: Sociedade Bíblica do Brasil, 2007, 1056p.
} 
esse processo repercute fortemente no campo religioso, provocando mudanças na correlação de forças entre os agentes religiosos.

As tensões e disputas no campo religioso, por sua vez, repercutem na concepção e no uso que as religiões, igrejas e grupos religiosos fazem do aparato midiático. A inserção ou apropriação de elementos religiosos pela mídia pode redundar numa concepção da mídia como substitutivo da religião. Por outro lado, a própria religião, nas suas mais diversas expressões, institucionalizadas ou não, ao recorrer à mídia como um instrumento estratégico de comunicação e de expansão, altera ou formata conteúdos e símbolos já tradicionais para adaptá-los à lógica empresarial e à linguagem midiática. Rituais religiosos são produzidos, muitas vezes, para se tornarem espetáculos midiáticos. (MOREIRA; LEMOS; QUADROS, 2012, p. 7)

Levando em conta tais elementos, o presente texto discutirá com alguns conceitos e concepções teórico-metodológicas, possíveis de serem observados e problematizados no fragmento de fonte escolhido, com abordagem direcionada para o campo da Análise do Discurso. Nesse intuito, a escrita percorrerá os seguintes caminhos: as instâncias de enunciação em termos de lugares, a intertextualidade, a pragmática e a deixis discursiva em Dominique Mainguenau; noções de discurso polêmico e de discurso lúdico, de Eni Orlandi; a questão da interdição e da vontade de verdade para Michel Foucault; os elementos de linguagem autorizada, ritos de instituição e força da representação segundo Pierre Bourdieau e, por fim, a linguagem como constituição de sujeitos, expressa em José Luiz Fiorin.

No campo da História, analisar um discurso significa trabalhar com o processo no seu contexto, daí a necessidade de recortar e manusear diferentes fontes. É preciso perceber a apropriação dos discursos sob diferentes formas porque as concepções epistemológicas das pessoas são diferentes. Uma vez que a análise do discurso tem sua matriz na lingüística, mas estamos falando na esfera da História, é preciso traçar alguns questionamentos e caminhos que ultrapassam uma análise de conteúdo. Afinal, um discurso não é somente textual e verbal, é também de imagem, gestos e expressão. (ROCHA; DEUSDARÁ, 2006, p. 10)

Logo, não há melhor ou pior gênero discursivo e não nos cabe julgar, apenas levar em conta que uma vez que a função de um discurso é gerar efeitos de sentido, cabe ao historiador, ao analisá-lo, compreender como os discursos são construídos, como o 
produtor de um discurso, o enunciador, provoca efeitos de sentido em cada receptor, o enunciatário. De modo geral, como discursos são produzidos e recebidos num determinado tempo e espaço.

O processo a ser percorrido envolve, nessa direção, sujeito e objeto, mediados pela palavra. Tendo em vista que um discurso é uma representação da realidade, cabe ao historiador munir-se de fundamentos epistemológicos de análise como a linguagem, o discurso e sua articulação com a História, construindo os eixos entre língua e linguagem. Trata-se de um olhar para o discurso como uma das possíveis dimensões da História, constituído a partir dos embates entre agentes históricos: econômicos, sociais, políticos, ideológicos, entre outros. Analisar um discurso, por conseguinte, significa contribuir para a pesquisa histórica através de uma metodologia e postura filosófica na realização de trabalhos e análises. Afinal, considerando o sujeito como agente histórico, automaticamente as fontes se tornam elemento de mediação entre diferentes dimensões da realidade histórico-social, tais como a matriz discursiva.

Por intermédio dos pressupostos metodológicos e dos recursos oferecidos pela Análise do Discurso, lançam-se algumas questões para a pesquisa histórica: de que modo os agentes históricos se autorepresentam? Como representam outros agentes? Ao se expressarem discursivamente como aparecem os traços de suas comunidades discursivas? Como são expressas e evidenciadas as relações de poder? Que perspectivas ideológicas estão inscritas nos discursos? A qual memória discursiva estão relacionados esses discursos? Como e por onde os mesmos circulam? Quais recursos retóricos argumentativos são utilizados e visam que tipo de efeitos de sentido? Com quais objetivos? A resposta pressupõe: uma abordagem interdisciplinar, um tratamento heterogêneo das fontes e uma flexibilidade do ponto de vista teórico e metodológico.

\section{"Igrejas alternativas": a expansão do cenário evangélico}

Lyndon de Araújo Santos propõe o entendimento do protestantismo como

Um movimento religioso e cultural sujeito às conjunturas históricas e às práticas sociais. Movimento que agregou traços e identidades com relação à experiência do sagrado, criou instituições e modos de ser, construiu espaços e redes de sociabilidade, produziu formas de pensar e sentir a realidade brasileira. (SANTOS, 2006, p. 224) 
A concepção de Santos remete à reflexão das religiões e das religiosidades como um campo de representações na história da sociedade brasileira. São cenários produtores de identidades e subjetividades religiosas, que devem ser pensados como práticas e representações culturais diante de processos mais amplos. $\mathrm{O}$ meio evangélico representa, portanto, um universo em constante mutação, produzindo diferentes sentidos para seus fieis.

Tanto a Gólgota quanto a Bola de Neve são igrejas evangélicas que emergiram no cenário contemporâneo nas últimas duas décadas. Todavia, existe uma necessidade de contextualização histórica das matrizes religiosas que as engendraram. Tendo em vista as dificuldades de situar igrejas alternativas contemporâneas como as duas em questão, estudos mais recentes como o de Magali do Nascimento Cunha, tem ajudado a redefinir o quadro das igrejas do protestantismo brasileiro, aproximando-se da análise e problematização dos objetos de pesquisa aqui tratados. Cunha definiu o quadro protestante em: a) Protestantismo Histórico de Migração, b) Protestantismo Histórico de Missão, c) Pentecostalismo Histórico, d) Protestantismo de Renovação ou Carismático, d) Pentecostalismo Independente ou Neopentecostalismo e e) Pentecostalismo Independente de Renovação. (CUNHA, 2007, p. 14-15)

O último grupo parece provavelmente ter engendrado as duas instituições. Para Cunha, o Pentecostalismo Independente de Renovação apareceu no final do século XX e ganhou força no início do XXI. Possui as características do neopentecostalismo como a ênfase no exorcismo, nos milagres e na guerra espiritual, mas difere dele por ter como público-alvo as classes médias e a juventude, estruturando seu modo de ser para alcançá-los, a exemplo da estética visual dos cultos e da membresia, dos estilos musicais, da linguagem utilizada, da influência e utilização dos mecanismos midiáticos, entre outros.

A Gólgota foi fundada na cidade de Curitiba em julho de 2001, desmembrada de uma instituição anterior chamada Zadoque. Criada pelo pastor Pipe, jovem criado na Igreja Presbiteriana do Brasil, formado em teologia, fã de música heavy metal, que montou a comunidade alegando não encontrar espaço em sua igreja para atender ao público jovem metaleiro, hardcore e gótico. No início, o grupo era formado por apenas sete pessoas que se reuniam na casa de um deles para discutir a Bíblia e praticar 
louvores evangélicos. Ao longo da última década foi constituída a primeira igreja de Gólgota, por aproximadamente 30 membros, já ocupando um espaço físico maior. Há cinco anos foi transferida para a Avenida Visconde de Guarapuava, no centro da cidade, contando hoje com aproximadamente 250 membros.

A instituição, em uma década, tem chamado a atenção dos meios de comunicação, travado embates com os meios evangélicos tradicionais em Curitiba e atraído jovens de diferentes tribos undergrounds. O pastor Pipe associou inclusão às diferenças, culto ao rock, imagem descontraída e linguagem informal como as grandes novidades da igreja. Os jovens participam de circuitos de motos e shows de heavy metal promovidos pela própria instituição. O templo parece uma garagem antiga, um barracão, bastante rústico, todo pintado de preto. O altar é um palco, que se assemelha ao de um show de rock. Os telões e as luzes completam o cenário. Nos fundos há uma espécie de cozinha, onde são vendidos refrigerantes, água e acessórios da comunidade como chaveiros, jaquetas, camisetas e cd's de bandas evangélicas.

O espaço de pertencimento e construção de identidades representa parte do empreendimento construído pela comunidade na última década. Para o pastor, o sucesso se deve à liberdade que a igreja dá a uma geração que não encontra espaço nos meios tradicionais evangélicos e que tem na instituição, especialmente por intermédio de seus rituais, a expressão viva dessa nova forma de ser evangélico. ${ }^{3}$

Diferentemente da Gólgota, que possui apenas um templo, em Curitiba, a Bola de Neve Church conta com cerca de 3000 templos espalhados pelo país e mais duas filiais no Peru e na Austrália. Fundada por um ex-membro da Igreja Renascer em Cristo, o apóstolo Rina, a Bola de Neve teve seu início em 1993, em São Paulo, com uma reunião de oração. Para os primeiros cultos não havia um lugar apropriado, então um empresário do mercado de surfwear ${ }^{4}$ abriu o espaço no auditório de sua empresa para a realização dos cultos.

Em Curitiba a igreja surgiu em 2004 com uma junção de aproximadamente 15 pessoas, que era realizada em uma sala de um apartamento. Com o tempo, o lugar começou a ficar pequeno, havendo uma mudança para um auditório de uma livraria

\footnotetext{
${ }^{3}$ URL: http://www.youtube.com/watch?v=eeuKOiyD81k Acesso em: 10 jun. 2012

${ }^{4}$ Surfwear é um estilo popular de vestuário casual, inspirada pela cultura do surfe. Muitas marcas relacionadas ao surfe surgiram de indústrias artesanais, suprindo surfistas com bermudas, roupas de mergulho, pranchas de surfe e outros acessórios.
} 
cristã e hoje, com aproximadamente 3000 membros, encontra-se sediada na Avenida Marechal Floriano Peixoto, no Boqueirão. ${ }^{5}$

A fim de cativar surfistas, skatistas, fisiculturistas, lutadores de jiu-jítsu e esportistas de modo geral, a Bola de Neve associou cuidado com a saúde, culto ao corpo, imagem descontraída e linguagem informal. Por isso, os fieis que dela fazem parte possuem visual despojado, usam tatuagens e piercings, vestem roupas descontraídas, aderem a acessórios da moda, pertencem a diferentes tribos e apresentam os mais diversificados perfis estéticos. Do mesmo modo que a Gólgota, a Bola de Neve Church já foi alvo de inúmeras críticas de outras igrejas, mas com uma proposta de atrair os jovens tem investido energia em cultos atrativos, músicas alternativas e linguagem diversificada.

Várias, portanto, são as características que diferenciam as igrejas alternativas das evangélicas tradicionais. Ao mesmo tempo, ajudam a caracterizar alguns dos motivos, pelos quais, a Bola de Neve em menos de uma década conquistou prestígio social e visibilidade pública, tornando-se um empreendimento religioso de expressividade, visitado a cada culto por inúmeros jovens, atraídos pela publicidade que anuncia a igreja como a grande novidade do mercado de bens simbólicos. A maioria dos jovens pratica esportes radicais e participa de torneios esportivos promovidos pela própria igreja. Os eventos de evangelização - luau e festivais musicais -, assim como campeonatos esportivos organizados pela igreja, ocorre na praia, o que contribui para reforçar a imagem e a identidade descontraída e informal do empreendimento. O templo é decorado com artefatos praianos para reproduzir o ambiente litorâneo. Espalhadas pela igreja há barracas de praia, pranchas de surfe e fotos de surfistas fazendo manobras radicais.

Esse é o cenário contemporâneo que tem redefinido perfis interessantes não apenas das novas igrejas, como também denota embates com outras instituições. Num país caracterizado pela forte presença católica, mas que tem se configurado como a nação mais pentecostal do planeta, é importante perceber os conflitos religiosos, as intolerâncias, os preconceitos, as construções identitárias, as pertenças culturais, as representações e simbologias. Nessa direção, tanto a Gólgota quanto a Bola de Neve, são igrejas que se colocam alicerçadas no campo do pentecostalismo independente de

\footnotetext{
${ }^{5}$ URL: www.boladenevecuritiba.com.br/sobre-a-igreja/ Acesso em: 10 jun. 2012
} 
renovação, igrejas alternativas que se destacam e atuam diferentemente das igrejas tradicionais do segmento evangélico. Pelo modo como circulam no meio evangélico, criam estratégias de inserção entre a juventude e difundem valores, princípios e condutas, por isso abre-se a possibilidade de abordá-las comparativamente em se tratando de produção histórica, apesar das inúmeras diferenciações existentes entre elas.

"As Igrejas dos roqueiros e dos surfistas": Possibilidades de abordagem midiática em Análise do Discurso

Considerando a noção de instâncias de enunciação em termos de lugares, segundo Dominique Mainguenau, parte-se do pressuposto do não julgamento de um discurso ou gênero discursivo, mas sim de que "o discurso tem que produzir um efeito de sentido entre enunciador e enunciatário. Afinal, os discursos são produções e não textos estáticos". (MAINGUENEAU, 1989, p. 29) No caso da entrevista emitida pelo SBT, fica evidente a existência de um discurso fundador (a Bíblia), cuja matriz discursiva é evangélica. Porém, observa-se a criação de códigos para dialogar com os enunciatários, como se observa na seguinte fala da apresentadora do programa:

Prancha de surfe e Bíblia. Piercing, tattoo e louvor, são comunicações com o divino sim, como você vai acompanhar no programa de hoje, que traz a presença de representantes de Igrejas muito diferentes daquelas que você está acostumado a visitar. Eu vou conversar hoje com o Pastor Pipe da Comunidade Gólgota pra falar de todo $\underline{\mathbf{O}}$ trabalho da comunidade, assim como o Fernando, da Igreja Bola de Neve. (...) Os conteúdos são voltados à religião e o pastor Pipe, formado em Teologia, explica bem as diferenciações. É muito interessante essa comunicação com Cristo, né, pastor?. (Grifos meus)

Uma vez que a entrevista é produzida em canal aberto, permitindo observar a linguagem falada, mas também a visual, o trecho acima permite sugerir a tentativa de suscitar curiosidade por parte dos enunciatários, no que diz respeito às duas igrejas em questão. Até porque, a entrevista foi produzida no mesmo mês da Marcha para Jesus, em Curitiba, evento que contou com a participação de inúmeros evangélicos da cidade, região e estado, destacando-se pela grande visibilidade do público jovem. Por isso, investe-se num discurso que não perde de vista seu campo ideológico, mas avança ao 
utilizar códigos como os estéticos: piercing, tattoo e louvor como novas comunicações com o divino, no terreno evangélico.

As instâncias de enunciação desdobram-se em outro conceito trabalhado por Mainguenau, o da intertextualidade. Um discurso modifica-se de acordo com as referências que faz a outras áreas, no interior dos campos, a esta ou aquela escola. Daí a necessidade de se captar o não dito, as entrelinhas de um discurso. Afinal, como a Análise do discurso relaciona-se com textos produzidos, verifica-se, por exemplo, que no quadro de instituições há forte restrição de enunciação, permitindo visualizar a cristalização de conflitos históricos, sociais, que delimitam um espaço próprio no interior de um interdiscurso limitado. (MAINGUENEAU, 1989, p. 23)

No caso da entrevista, observando as entrelinhas, verifica-se a questão cultural como elemento bastante forte. Buscando o reconhecimento, legitimidade e eficácia discursiva, atingindo um determinado público, o jovem, há momentos em que ocorre, inclusive, a deslegitimação de outros discursos religiosos; e isso é feito por intermédio de uma crítica indireta ao tradicionalismo de algumas igrejas evangélicas e da valorização de outras formas de expressão de fé, como as utilizadas nas igrejas alternativas. A seguinte fala do pastor Pipe exemplifica:

Hoje a gente vive um momento histórico porque as gerações têm mudado muito bruscamente essas questões de cultura. Então, há uma geração que não tem se adaptado a esse modelo tradicional de igreja que vem caminhando durante o século. É uma geração que tem uma nova linguagem, que tem uma nova forma de entender essa questão com o divino! É uma nova fé, um novo tema, é uma forma mais descolada de entender as questões de Deus! (Grifos meus)

O fragmento permite a identificação do quanto além do movimento religioso protestante ter nascido plural e pluricentrado, demonstra como cada igreja cristã justifica a sua existência ao tentar, à sua maneira, levar adiante a missão que entende ter-lhe sido confiada por Jesus. No protestantismo, significou buscar a conversão de indivíduos e a sua salvação da condenação eterna, mediante a fé no filho de Deus.

Nesse sentido, verifica-se o quanto as religiões e religiosidades apontam um campo de representações na história da sociedade brasileira. São cenários produtores de identidades e subjetividades religiosas, que devem ser pensados como práticas e representações culturais diante de processos mais amplos. Assim, o meio evangélico 
representa, nas últimas décadas, um universo em constante mutação, levando as instituições religiosas a redefinirem inúmeras de suas concepções e práticas, produzindo diferentes sentidos para seus fieis. Por isso, a religiosidade vem sendo cada vez mais influenciada, por exemplo, pela mídia, diante da crescente variedade de opções de estilos de vida num mundo em que tudo se mistura; isso torna possível indagar sobre qual é o lugar específico da religião, os significados de ser evangélico atualmente.

Por conseguinte, apesar do lançamento de novos códigos de linguagem, é preciso não esquecer que toda atividade da linguagem é inscrita em espaços institucionais. Nesse sentido, entra em voga a noção de pragmática, para Mainguenau. “Cada ato de falar é inseparável de uma instituição" (MAINGUENEAU, 1989, p. 18), desenhando uma ideia de contrato. O sujeito ao enunciar presume um ritual social de linguagem implícito e partilhado pelos interlocutores; a enunciação produzida é colocada em um contrato que credita ao pastor, por exemplo, o lugar de detentor do saber. Isso fica bastante explícito em vários momentos da entrevista quando a entrevistadora parece dar mais credibilidade às falas do pastor Pipe do que as do membro Fernando; é como se o primeiro estivesse mais apto a falar.

Isso de certa forma é bastante curioso, pois a entrevista possibilita perceber três níveis de discurso: o cristão; o evangélico brasileiro; e o de Gólgota, expresso por Pipe, que rompe com vários elementos, inclusive dos dois primeiros. Tal cenário expressa a minimização do tradicional rigor puritano e o sectarismo de alguns grupos, especialmente na última década, que tem se traduzido num expressivo crescimento numérico dos segmentos evangélicos no Brasil. As constantes transformações sociais e culturais são marcas de reorganização das igrejas protestantes. Por isso, é possível admitir que o radicalismo, especialmente com relação ao uso de determinadas vestimentas, o conteúdo musical escutado, a linguagem litúrgica de um determinado público, tem participado da afirmação de novas identidades culturais, que têm sido incorporadas às igrejas, quando não matizado novas formas de participação.

Determinados grupos têm explicitado amplas transformações sociais e levado em conta exigências dos sujeitos que parecem não se enquadrar mais em dados meios tradicionais, nem tampouco resolverem sozinhos seus problemas e anseios cotidianos reais e não apenas espirituais; daí o fato de algumas instituições evangélicas, em alguns casos, estabelecerem uma espécie de fascinação pela "mundanidade" que os envolve. 
Parece ser nesse quadro de desinterdição de áreas da mundanidade provada pelos evangélicos brasileiros, que se apresenta o movimento cultural evangélico da Gólgota, admitido nos discursos do pastor Pipe.

Contudo, mesmo com Pipe rompendo uma série de precedentes em sua fala (e não o fazendo dentro da instituição) é como se ele estivesse autorizado institucionalmente a falar, recebendo credibilidade para tal. Os seguintes trechos da fala da apresentadora exemplificam: "Interessante essa história dos cultos também na Bola de Neve, porque o Fernando não é pastor, né Fernando?"; ou, ainda, "Mas isso que o Fernando está falando não gera o que nós temos hoje no Brasil de muitas igrejas desvirtuarem o que diz a própria palavra, pastor Pipe?”. (Grifos meus)

Tais fatores, essencialmente o de Pipe questionar e romper com vários precedentes religiosos e não o estar fazendo no espaço institucional, permite a consideração da noção de deixis discursiva, problematizada por Mainguenau. Para ele, "uma formação discursiva não enuncia a partir de um sujeito, de uma conjuntura histórica e de um espaço objetivamente determináveis do exterior, mas por atribuir-se a cena que sua enunciação ao mesmo tempo produz e pressupõe para se legitimar" (MAINGUENEAU, 1989, p. 25). É a questão do ETHOS=voz, que na esfera religiosa, por exemplo e a exemplo do pastor Pipe, representa a hipótese de que a fé em um discurso está relacionada a possibilidade de que os sujeitos nele se reconheçam. Alguns trechos da fala de Pipe elucidam: “As igrejas emergentes, que são as igrejas que têm trazido essa nova proposta de trabalho, elas têm dado liberdade pra essa geração que está aî"; ou, quando perguntado pela apresentadora se pastor sofre muito, principalmente os que têm cabelo comprido, ele responde rindo: "Nem por isso! Os irmãos são uma benção mesmo na nossa vida!”. (Grifos meus)

As igrejas emergentes, alternativas, no cenário atual, também são admitidas como tribos evangélicas (roqueiros, motoqueiros, cabeludos, tatuados, surfistas, regueiros, entre outros), que formaram as igrejas ou ministérios alternativos, voltados especialmente para pessoas com faixa etária de 20 a 45 anos. Nessas congregações os cultos são caracterizados pela informalidade, com comunicação muito marcada por gírias, com louvores em ritmo de rock e reggae e rituais em forma de espetáculo. As tribos resultam da diversidade étnica, religiosa, de situação financeira, de escolaridade e do estilo de vida urbana contemporânea. São organizadas a partir do compartilhamento 
de modos de vida, formados por atitudes, padrões de consumo, gostos, crenças e vínculos de sociabilidade. Nas palavras de Cunha: "São agrupamentos de pessoas organizados a partir da identidade evangélica - pessoas que se converteram ou aderiram a uma agremiação evangélica - e da adoção de um modo de vida gospel (inserção na modernidade e liberalização de costumes)". (CUNHA, 2007, p. 167)

Como aparece no discurso de Pipe, a questão da identidade e do pertencimento nas igrejas emergentes, expressa o fato de que determinadas instituições dão certa liberdade para uma geração que não se encaixa nos meios tradicionais de expressão de fé. $\mathrm{O}$ argumento do pastor demonstra o quanto o campo religioso é marcado por turbulências e pluralismos, cujas igrejas alternativas disputam espaços e constroem sentidos religiosos diversos, utilizando para tanto inúmeras estratégias para que isso aconteça. Exemplificando a presença da juventude como público-alvo, cultos alternativos, linguagem informal e ferramentas como a internet como símbolos de construção identitária.

Trechos extraídos da fonte, caracterizados acima através de elementos abordados por Mainguenau, aliam-se a outros dois conceitos fundamentais, discutidos por Eni Orlandi (1983, p. 141-142): o de discurso polêmico e o de discurso lúdico. No que se refere à entrevista, pode-se dizer que possibilita a identificação das duas tipologias. Problematizando os efeitos de sentido presentes na entrevista, é possível perceber que os contextos se encontram em constante tensão, interação e, até mesmo, conflito. Por isso da impossibilidade, da ilusão de um sentido literal. $\mathrm{O}$ discurso polêmico, portanto, mistura-se com o lúdico, apontando a relação de dominância de um sentido com outro, preservando vários ecos. Como admite Orlandi: “A função metodológica das regras conversacionais é a seguinte: dados um sentido literal e um contexto, pode-se determinar através da regra a variação de sentido. Essa função é interpretativa, a de derivar do sentido literal as variações de sentido, regulando a ação dos contextos". (ORLANDI, 1983, p. 154)

$\mathrm{Na}$ entrevista a questão da imagem, do visual, da estética, como já dito, é bem representativa. O visual, a roupa, vira discurso, complementando a própria fala. Há, por conseguinte, uma polêmica discursiva, travada através da representação de um discurso fundador, de elementos presentes em igrejas evangélicas brasileiras tradicionais, que são relativizados através de um discurso lúdico, visualizado nas falas de Pipe e Fernando, 
expressos também na imagem, visual, vestimenta dos dois. Há polêmica também entre as próprias falas dos entrevistados, em muitos momentos, suscitadas pela própria entrevistadora. Apesar de ambos pertencerem a um mesmo cenário, a credibilidade autorizada parece ser dada ao pastor Pipe; tornando, em alguns momentos, as falas de Fernando questionáveis. Os seguintes trechos, um expresso na pergunta da entrevistadora e outro na resposta do entrevistado Fernando, elucidam a questão:

Apresentadora: Fernando, irmãos tatuados e que usam piercing, a interpretação da bíblia como o pastor Pipe disse pra gente, é a mesma interpretação da Bola de Neve ou não? Por que as pessoas que estão te assistindo agora se eu disser que você faz parte de uma igreja chamada Bola de Neve não vão entender nada! Sendo que vocês usam a bíblia também, né? E são cem por cento ortodoxos? Fernando: Sim! É uma Igreja Evangélica normal, como qualquer outra, só que a visão da tatuagem não é tão natural quanto em outras. Tem uma outra interpretação, a de que a gente tem que tá em paz pra fazer uma tatuagem! Contanto que não tenha apologia à droga, violência e sexo, tá tranqüilo! (...) A ideia era pegar o pessoal mais jovem, mais marginalizado, que as igrejas mais tradicionais às vezes não aceitariam. E Deus deu uma revelação e a igreja anda de acordo com isso. Conforme o pastor falou pra mim falar: a gente é um bando de louco que só faz o que Deus quer e o que Deus pede!. (Grifos meus)

A vestimenta do pastor Pipe e do membro da Bola de Neve durante a entrevista, bem como a linguagem e argumentos utilizados, retomam a discussão sobre identidade e pertencimento, denotando o quanto o visual, estético e retórico viram linguagem simbólica, representação. Por conseguinte, os novos tempos, as redefinições no campo religioso, as novas expectativas dos fieis quanto à sua fé, acarreta em investimento, expansão, representatividade e visibilidade das igrejas perante a sociedade. Percebe-se, com isso, que igrejas alternativas apesar de sofrerem críticas das mais tradicionalistas, parecem ter apoio suficiente para se manterem e ampliarem sua presença no cenário evangélico; pois, como admite Cunha, "num mundo cheio de pecados, ser um cristão verdadeiro é um dever de quem pretende se salvar. Agir como um maluco de Cristo talvez seja uma forma de não se perder”. (CUNHA, 2007, p. 168)

Nesse contexto de expansão dos segmentos evangélicos, as duas instituições religiosas incorporam o discurso pós-moderno da diferença às suas práticas e a seus discursos identitários. Cedem espaço aos "de fora" não somente de outras igrejas, mas da própria sociedade, outsiders que não se encaixariam nos padrões mais convencionais, 
especialmente na apresentação estética de si na vida cotidiana. Existe o preconceito que sofreriam as tribos ao adotarem um determinado estilo comportamental tido como alternativo; o que tem provocado conflitos no meio evangélico quando os "convertidos" se vêem obrigados a mudar o estilo para que não se sintam desconfortáveis num meio onde devem apresentar-se como "um novo ser em Cristo".

Retornando à análise do discurso para perceber tais nuances, a questão da legitimidade do "diferente", mais acentuada pela apresentadora com relação ao pastor do que de Fernando, observa-se outra evidência relacional de conceitos. Trata-se da noção de interdição, proposta por Michel Foucault, complementada pelo que considera a vontade de verdade. Foucault argumenta que na chamada interdição, o enunciador não tem o direito de dizer tudo o que deseja, o que faz com que exista um tabu do objeto, mais um ritual da circunstância, mais um direito de falar exclusivo do sujeito. Portanto, o discurso sempre tem uma ligação com o desejo e com o poder. Na vontade de verdade existe uma separação entre a razão e o que é verdadeiro e falso, constituindo uma nova forma de saber. (FOUCAULT, 2005, p. 3)

No caso da fonte aqui discutida, verifica-se indiretamente a existência de um sistema de exclusão apoiado em instituições e práticas religiosas. Existem procedimentos e controles internos, expressos em falas como as de Pipe ao recorrer ao discurso fundador: resgata pilares cristãos como a bíblia, mas ao interpretá-la relativiza valores e costumes, estabelecendo críticas aos evangélicos brasileiros mais tradicionais. Tal tensão, observada na entrevista, por intermédio dos discursos, sugere que "o novo não está no que dizem, mas no acontecimento de sua volta”. É produzido, assim, o que Foucault chama de jogo da repetição (No caso da fonte trabalhamos com a ideia, elaborada por Magali Cunha, de "vinho novo em odres velhos"): forma de reatualização permanente das regras. Foucault admite que isso acontece por conta da disciplina, pois existe uma imposição de regras aos sujeitos do discurso, expressas através do ritual, das sociedades do discurso, dos grupos doutrinários e da apropriação social dos discursos. A seguinte fala de Pipe exemplifica:

“A gente não faz uma reinterpretação da Bíblia. É como eu falei: a questão dos usos e costumes sempre foi livre na história das igrejas. A gente nunca impôs isso! Quem impôs, impôs e impôs da maneira errada! Tragédia na história é quando a igreja tenta impor as teses culturais sobre os povos!"'. (Grifos meus) 
$\mathrm{O}$ argumento de Pipe expressa um quadro cujas igrejas alternativas se apresentam como instituições que respeitam o "diferente", em meio às mais tradicionais que adotam costumes e culturas enraizadas no "puritanismo" evangélico, especialmente os segmentos pentecostais clássicos. O preconceito sofrido pelo meio underground, é o que levaria esses diferentes à identificação religiosa com igrejas "alternativas". De modo geral, as duas instituições religiosas são lugares de práticas e representações socioculturais e apresentam-se (e seus membros se autorepresentam), pelo menos parcialmente, como instituições assentadas numa série de pautas diferenciais em relação às outras igrejas do campo evangélico; mas, ao mesmo tempo, mantêm-se marcadas pela pertença ao mundo dos evangélicos, suas raízes espirituais e teológicas.

A própria noção sociológica de tribo, marca uma "novidade" identitária em meio a outras igrejas; inclusive, contrastando com a concepção de tantas outras, afirmando, no discurso e nas práticas, que a aparência (vestimentas e adornos) não é determinante para a santidade na vivência da fé. É preciso não perder de vista, entretanto, que, ao defender o visual underground, é como se deixassem o caminho livre para a própria "doutrina" cristã. Ao mesmo tempo, corroboram com o argumento de Pipe de que as igrejas emergentes não estão apenas contestando os meios religiosos tradicionais, nem tampouco reinterpretando a bíblia, mas promovendo uma redefinição religiosa.

Esse cenário, juntamente com os trechos da entrevista, abordados até aqui, podem ser amarrados com os elementos de linguagem autorizada, ritos de instituição e força da representação, discutidos por Pierre Bourdieu. A entrevista nos conduz à percepção de que o enunciador está num cenário; o sujeito está num lugar, num contexto. Como admite Bourdieau, "quando você é instituído passa a representar aquele que te instituiu" (BOURDIEU, 1996, p. 89). A fala de Fernando, anteriormente, apontou claramente a existência de condições do enunciador de dizer o que disse: “Conforme o pastor falou pra mim falar". (Grifos meus) Diferentemente de Pipe, que é o pastor da igreja e, por isso, fala em nome próprio e também da instituição. "A questão dos usos e costumes sempre foi livre na história das igrejas. A gente nunca impôs isso! Quem impôs, impôs e impôs de maneira errada". (Grifos meus)

Tais elementos também convergem com a ideia de poder simbólico, para Bourdieu. Sugere-se uma noção de identidade individual e coletiva, de pertencimento. 
A valorização da estética e os novos recursos de formatação dos cultos, a tal questão da cultura, levantados por Pipe, permitem perceber o quanto a linguagem e suas representações têm uma eficácia também simbólica na construção da realidade. Nas palavras de Bourdieu: “Ao estruturar a percepção que os agentes sociais têm do mundo social, a nomeação contribui para constituir a estrutura desse mundo, de uma maneira tanto mais profunda quanto mais reconhecida (isto é, autorizada)" (BOURDIEU,1996, p. 81)

Um discurso deve ser não apenas conhecido, mas reconhecido. Logo, num culto, numa cerimônia religiosa, representa-se um mistério da magia através da qual o representante constitui o grupo que o constitui. "O mundo é minha representação", como admite Bourdieu, expressando a validade e eficácia de um discurso ritual. No caso de Pipe e de Fernando, especialmente do primeiro, uma vez que não estão num culto e sim numa entrevista em rede nacional, precisam valer-se do poder da retórica, fazendo com que os discursos produzam efeitos de sentido para quem os recebe. Afinal, um discurso de autoridade não pode ser apenas compreendido, tem que ser reconhecido pelos sujeitos.

Nessa direção, as entrelinhas da entrevista indicam certa crise das instituições religiosas tradicionais e os entrevistados se apóiam nisso para criar e difundir seus discursos. Pastor, fieis e discursos religiosos e/ou institucionais, assim, contrastam com religiosidade e subjetividade, com controle e objetivo. Nesse sentido é que se torna possível a percepção de que os ritos de instituição, de que fala Pierre Bourdieu, tendem a tornar naturais e integrantes inúmeras oposições. Até porque instituir é consagrar, santificar, naturalizar um estado de coisas; o ato de comunicação em que se notifica a identidade, o reconhecimento, o pertencimento coletivos; "Torne-se o que você é" (BOURDIEU, 1996, p. 102). É nesse sentido que o ritual da estética, da roupa passa a ser discurso e um determinado público tenta ser atingido por intermédio dessa ideia. Como já expresso anteriormente numa fala de Pipe: "Não é contestação. É a liberdade de expressar o seu louvor e a sua devoção a Deus dentro daquilo que o contexto cultural deles dá liberdade pra isso". (Grifos meus)

O jogo de forças entre o objetivo e o subjetivo lança ao historiador a necessidade não de escolher entre um e outro, mas sim de relacioná-los. Pois, como aponta Bourdieu acerca da força da representação, 
O efeito de conhecimento exercido pelo fato da objetivação no discurso não depende apenas do reconhecimento concedido àquele que o detém; depende também do grau com que o discurso anunciador da identidade do grupo está fundado na objetividade do grupo ao qual está endereçado, ou seja, tanto no reconhecimento e na crença que lhe atribuem os membros desse grupo como nas propriedades econômicas ou culturais por eles partilhadas, sendo que a relação entre essas mesmas propriedades somente pode ser evidenciada em função de um princípio determinado de pertinência. (BOURDIEU, 1996, p. 111)

O apontamento de Bourdieu chama a atenção para a força da representação, o mundo religioso representado por concepções e práticas religiosas, nesse caso. Os discursos dos líderes religiosos valorizam o "diferente" na prática litúrgica e no modo de ser igreja; posicionam-se como evangélicos no sentido da prática da fé, da valorização de sentidos cristãos inalteráveis; deixam claro que o espaço é o de prática da fé e qualquer indivíduo, independentemente de sua aparência, poderia frequentar igrejas sem se sentir discriminado, o que não aconteceria em outras instituições evangélicas. Tudo isso, novamente, legitima uma determinada ideia de expansão religiosa do segmento evangélico; no bojo desse processo, as igrejas surgiriam como "igrejas modernas", não-preconceituosas e mais atentas ao "espírito do tempo", às mudanças identitárias e culturais do mundo contemporâneo.

Importante perceber que a eficácia de um discurso é dada pelo conhecimento e reconhecimento do mesmo por parte dos fieis. Há a necessidade de afirmar o quanto os discursos pretendem representar os fieis e o que acreditam. Nesse sentido, as possibilidades oferecidas pela fonte, no que diz respeito às tipologias discursivas e os elementos produzidos por Bourdieu, auxiliam na compreensão do que José Luiz Fiorin chama de linguagem como constituição de sujeitos. Para ele, é preciso saber "qual é o lugar das determinações ideológicas neste complexo fenômeno que é a linguagem, analisar como a linguagem veicula a ideologia, mostrar o que é ideologizado na linguagem". (FIORIN, 1988, p. 7)

A questão dos três discursos, verificada especialmente numa análise das entrelinhas da entrevista, mencionada anteriormente, relaciona-se diretamente com o conceito de Fiorin. Tanto Pipe quanto Fernando, em suas falas, indicam a presença da ideologia cristã. No entanto, ao expressar uma linguagem estilística (na fala e no visual), Pipe rompe com uma série de elementos, especialmente os mais tradicionais, no que se 
refere à doutrina cristã e ao cenário evangélico brasileiro. A seguinte fala de Pipe, quando questionado pela entrevistadora acerca da bíblia lida e estudada na Igreja, se é a mesma utilizada nas Igrejas Evangélica e Católica, auxilia na compreensão:

Em questões teológicas nós somos ortodoxos cem por cento! Absolutos! Não cremos em nada de diferente do que a bíblia crê em ortodoxia. Agora em questões culturais, em eclesiologia, que é o termo que se usa, você vai trazer um formato de culto. Biblicamente falando não existe um absoluto à forma como o culto deve ser apresentado. (Grifos meus)

Pipe valorizando o que chama de subcultura ou cultura underground da exclusão, procura uma afirmação identitária diferencial. O que pode ser apontada através das tensões que participa com o meio evangélico, como por exemplo, em relação ao significado do 'diferente'. Para ele, o problema não está na Bíblia e sim na dificuldade que as pessoas têm de aceitar os "diferentes". A cultura está envolta principalmente no conceito de estética difundido pelas Igrejas Alternativas. Afinal, a grande maioria convertida para os meios tradicionais é convidada a mudar o seu estilo de vida e, também, visual, pois é "nova criatura em Cristo"; o que, em tese, não é pauta nas igrejas emergentes.

As igrejas emergentes percebem o preconceito como algo social, que penetra no interior das igrejas e faz com que as pessoas não aceitem o "diferente". Por isso, para dar consistência ao que acreditam, investem na ideia de leitura filosófica da bíblia, com uma chamada contextualização histórica, procurando convencer os jovens de que a religião não é algo atrasado, conservador, que deve ser odiada. Na Golgota, por exemplo, são valorizadas questões teológicas, livros, contexto histórico. Não é, como admite Pipe, "uma contestação, é uma redefinição religiosa e uma nova formatação de culto, um cristianismo pensante". (Grifos meus)

Indiretamente, há uma preocupação das duas igrejas, especialmente da Golgota, em polemizar com a chamada "leitura ao pé da letra" da bíblia, criticando as articulações de poder entre vários líderes religiosos, que utilizam passagens bíblicas de modo descontextualizado para promover convencimentos. Para identificação dos fieis contam com o apoio da liturgia e dos cultos. Apesar de existirem integrantes de diversas faixas etárias, procedências, grupos, entre outros, o alvo mesmo seria o jovem underground. De modo geral, usar o meio, o estilo, o público, como forma de 
evangelização através da linguagem e visual; procurar fazer com que o jovem não desista do meio evangélico depois de "nascer em Cristo". Buscando legitimando para o discurso, Pipe exemplifica: "somos radicais no visual porque somos radicais na prática cristã. Assim como o estilo impacta, a fé também deve impactar!". (Grifos meus)

Em linhas gerais, todas as considerações realizadas até aqui tiveram o objetivo de demonstrar, sobretudo através da fonte citada, que se trata de uma investigação que busca melhor conhecimento não somente da história religiosa brasileira, bem como compreender outros aspectos a ela relacionados, suas performances nos mundos social, econômico e cultural. Pretende-se contribuir na busca por respostas a problemas atuais do cenário religioso brasileiro, podendo ser vislumbrada a partir de algumas reflexões sobre o próprio significado de ser evangélico. Até porque, ao longo das últimas décadas, ele tem adquirido novos sentidos, contribuindo, aproximando e permitindo o diálogo entre diferentes instituições religiosas - desde as mais tradicionais, até as mais alternativas - e o próprio universo acadêmico que lhe empresta uma atenção cada vez mais merecida.

\section{Considerações Finais}

Esse texto é uma pequena amostra de como o conjunto das questões, conceitos e elementos abordados foram possíveis tendo em vista a escolha de uma fonte, constituída por modalidade de gênero discursivo, que permitiu pontuar tensões entre os sujeitos dos discursos e também outros discursos, entre o dito e o não dito, bem como a relevância das entrelinhas.

A análise de discurso é apenas uma, dentre outras tantas possibilidades, para problematizar como a comunicação é vista enquanto processo produtor de significação. São processos de identificação de sujeitos, argumentação, subjetivação, construção da realidade, uma vez que não existe linguagem neutra, cabendo ao historiador, munido da postura e técnicas, pensar no movimento da linguagem em sua dimensão histórica. Afinal, as palavras são produtoras de sentido quando aparecem diretamente ligadas ao intercâmbio que a vida social expõe, dando proporções de passado, presente e futuro. 
Importante ferramenta metodológica, a Análise do Discurso, nesse ensaio, serviu para auxiliar na problematização de como instituições religiosas ditas alternativas ou pentecostais independentes podem servir de exemplo, expressão, representação das redefinições religiosas da contemporaneidade. Ademais, são reflexos da explosão, da expansão do cenário e das novas formas de ser e de viver dos evangélicos, especialmente nas últimas duas décadas.

\section{Referenciais}

Fonte

Programa Destaque SBT, Conheça as Igrejas dos Roqueiros e dos Surfistas, 31/05/2010. Disponível na rede.

URL: http://www.youtube.com/watch?v=eeuKOiyD81k

\section{Referências Bibliográficas}

A BÍBLIA SAGRADA. Traduzida em Português por João Ferreira de Almeida. Revista e Corrigida no Brasil. Ed. 1995. São Paulo: Sociedade Bíblica do Brasil, 2007, 1056p.

BOURDIEU, Pierre. A economia das trocas lingüísticas. São Paulo: Edusp, 1996.

CUNHA, Magali do Nascimento. A explosão gospel - Um olhar das ciências humanas sobre o cenário evangélico no Brasil. Rio de Janeiro: Mauad, 2007.

FOUCAULT, Michel. A Ordem do discurso. São Paulo: Ed. Loyola, 1998.

FIORIN, José Luiz. Linguagem e ideologia. São Paulo: Ática, 1988.

MAINGUENEAU, Dominique. Novas tendências em análise do discurso. Campinas: Pontes, 1989.

MOREIRA, Alberto da Silva; LEMOS, Carolina Teles; QUADROS, Eduardo de Gusmão (Orgs.). A religião na mídia e a mídia na religião. Goiânia: Gráfica e Editora América, 2012.

ORLANDI, Eni Pulcinelli. A Linguagem e seu funcionamento. São Paulo: Brasiliense, 1983.

ROCHA, Décio \& DEUSDARÁ, Bruno. Análise de Conteúdo e Análise do Discurso: aproximações e afastamentos na (re)construção de uma trajetória. São Paulo: D.E.L.T.A, 2006.

SANTOS, Lyndon de Araújo. As outras faces do sagrado: protestantismo e cultura na Primeira República brasileira. São Luís: Edufma, 2006.

URL: www.boladenevecuritiba.com.br/sobre-a-igreja/ Acesso em: 10 jun. 2012

Recebido: 11/03/2014

Received: 03/11/2014

Aprovado: 19/07/2014

Approved: 07/19/2014 